\title{
Resistance to antibiotics in the normal flora of animals
}

\author{
Henning SøRUM*, Marianne SUNDE \\ Norwegian School of Veterinary Science, Post Box 8146 Dep., 0033 Oslo, Norway
}

(Received 18 December 2000; accepted 8 March 2001)

\begin{abstract}
Summary - The normal bacterial flora contains antibiotic resistance genes to various degrees, even in individuals with no history of exposure to commercially prepared antibiotics. Several factors seem to increase the number of antibiotic-resistant bacteria in feces. One important factor is the exposure of the intestinal flora to antibacterial drugs. Antibiotics used as feed additives seem to play an important role in the development of antibiotic resistance in normal flora bacteria. The use of avoparcin as a feed additive has demonstrated that an antibiotic considered "safe" is responsible for increased levels of antibiotic resistance in the normal flora enterococci of animals fed with avoparcin and possibly in humans consuming products from these animals. However, other factors like stress from temperature, crowding, and management also seem to contribute to the occurrence of antibiotic resistance in normal flora bacteria. The normal flora of animals has been studied with respect to the development of antibiotic resistance over four decades, but there are few studies with the intestinal flora as the main focus. The results of earlier studies are valuable when focused against the recent understanding of mobile genetics responsible for bacterial antibiotic resistance. New studies should be undertaken to assess whether the development of antibiotic resistance in the normal flora is directly linked to the dramatic increase in antibiotic resistance of bacterial pathogens. Bacteria of the normal flora, often disregarded scientifically, should be studied with the intention of using them as active protection against infectious diseases and thereby contributing to the overall reduction of use of antibiotics in both animals and humans.
\end{abstract}

normal bacterial flora / antibiotic resistance / feed additives / genetic exchange / preventive management

Résumé - Résistance aux antibiotiques dans la flore normale des animaux. La flore bactérienne normale contient des gènes de résistance aux antibiotiques, à des niveaux divers, même chez des individus n'ayant jamais été exposés à des préparations commerciales d'antibiotiques. Plusieurs facteurs semblent augmenter le nombre de bactéries résistantes aux antibiotiques dans les selles. Un facteur important est l'exposition de la flore intestinale aux antibiotiques. Les antibiotiques utilisés comme additif alimentaire semblent avoir un rôle important dans le développement de la résistance aux antibiotiques dans la flore bactérienne normale. L'utilisation de l'avoparcine comme additif alimentaire a montré qu'un antibiotique considéré sans danger est responsable de l'augmentation des taux de résistance aux antibiotiques chez les entérocoques de la flore normale d'animaux ayant reçu de

* Correspondence and reprints

Tel.: (47) 22964770; fax: (47) 22964818; e-mail: Henning.Sorum@ @eths.no 
l'avoparcine, et peut-être chez des humains consommant des produits dérivés de ces animaux. Cependant, d'autres facteurs tels que le stress dû à la température, à une forte densité d'animaux, et au type d'exploitation semblent également contribuer à l'apparition de résistance aux antibiotiques dans la flore bactérienne normale. Parmi les études portant sur le développement de la résistance aux antibiotiques dans la flore normale des animaux ces 40 dernières années, peu d'études ont été focalisées sur la flore intestinale. L'apport des résultats d'études anciennes est précieux dans la compréhension récente du rôle des éléments génétiques mobiles dans la résistance aux antibiotiques. De nouvelles études devraient être entreprises afin de montrer si le développement de la résistance aux antibiotiques dans la flore normale est directement lié à l'augmentation spectaculaire de la résistance aux antibiotiques chez les bactéries pathogènes. Les bactéries de la flore normale, souvent négligées scientifiquement, devraient être étudiées dans le but de les utiliser comme protection active contre les maladies infectieuses, contribuant par là même à la diminution de l'utilisation d'antibiotiques chez l'animal et chez l'homme.

flore bactérienne normale / résistance aux antibiotiques / additif alimentaire / échange génétique / prévention

Table of contents

1. Introduction ...................228

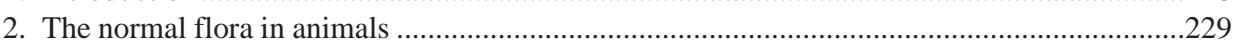

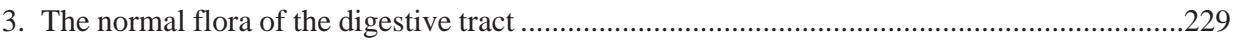

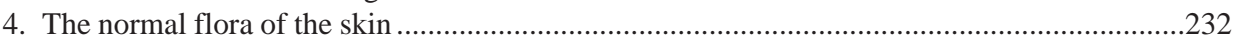

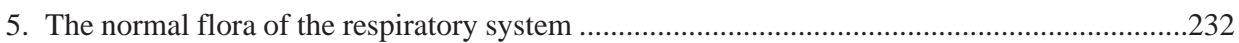

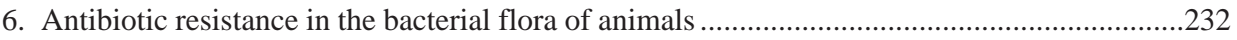

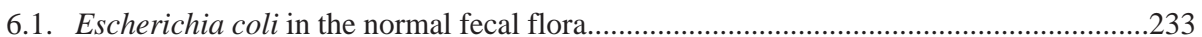

6.2. Antibiotic resistance in $E$. coli of the normal fecal flora ................................................23

6.3. Environmental stress and antibiotic-resistant bacteria in swine .....................................234

7. Transfer of antibiotic-resistant bacteria from animals to man...................................................235

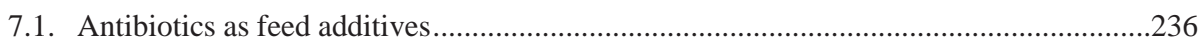

7.2. Source of antibiotic resistance genes in the normal bacterial flora .................................237

7.3. Consequences of antibiotic resistance in the normal flora of animals..............................238

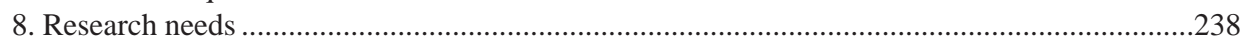

\section{INTRODUCTION}

Bacteria are present in all natural environments where eucaryotic cells live and in many habitats considered to be too extreme for occupation by eucaryotic cells. The widespread occurrence of bacteria extends to regions ranging from the upper atmosphere to sediments on the ocean bed. Animals of every kind are in continual contact with microorganisms. Bacteria occur most abundantly in habitats where they find food, moisture and a temperature appropriate for their growth and multiplication. Since the conditions that favour the survival and growth of many microorganisms are those under which higher organisms normally live, it is obvious that mammals live among a multitude of microbes $[45,55]$.

Mammalian bodies provide favorable environments for the growth of microorganisms, and microorganisms enter into various degrees of symbiotic relationships with the host. The microflora present at any site in a healthy animal is collectively referred to as the normal flora. Many of these microorganisms are anaerobes. Paradoxically, they 
enjoy a commensal existence with a host dependent upon oxygen for its survival.

The definition of the normal animal bacterial flora may vary. In general, the bacteria of the normal flora can be divided into symbionts - which benefit both themselves and the host, in commensals - which do not seem to be of any benefit to the host, and in opportunists which may harm the host and produce disease under certain circumstances. Wray [63] defines opportunistic pathogens that can be isolated from an animal without signs of infection as part of the normal flora.

The animal body cannot be considered as one uniform microbial habitat. Each region differs from the others thus creating a selective environment where certain microorganisms are favoured more than others. The skin, the oral cavity, the gastrointestinal tract, the respiratory tract, and the genito-urinary tract are environments where conditions favour certain types of microorganisms. The organ systems of mammals which contain the most diverse and complex bacterial flora are the skin and the digestive system.

Antibiotics have mainly been used to cure infections caused by pathogenic bacteria in humans and animals. Knowledge about the mobile genetic background of antibiotic resistance has successively resulted in a larger focus on bacterial ecology. For pathogens, the normal commensal bacterial flora of the various parts of the animal is of interest as potential genetic partners in the "trading" of antibiotic resistance genes. Treating an animal with an antibiotic will automatically kill a larger portion of the normal flora. The various known and unknown variants of bacteria of the normal flora will, if possible, defend themselves on the basis of resistance features. Studies on resistance of bacteria from animals often include pathogenic bacteria isolated from sites of infection while resistance in normal flora bacteria not associated with infections are seldom studied.
Genetic elements involved in antibiotic resistance have usually been characterized from human pathogens. Resistance elements like integrons and transposons, detected in commensals, seem to be identical to those commonly found among clinical isolates [51]. With more knowledge on the mobile genetic systems in bacteria, more emphasis should be placed on antibiotic resistance of the normal flora in the future.

\section{THE NORMAL FLORA \\ IN ANIMALS}

Various skin surfaces and mucosal membranes in animals including the contents of the digestive tract have a normal bacterial flora with a characteristic composition. There seems to be tissue tropism related to the bacteria in the normal flora. In general there are more Gram-positive bacteria like staphylococci and corynebacteria on the skin compared to the flora of the intestines which contains various groups of bacteria among which enterobacteria, as for instance Escherichia coli, and various anaerobes are Gram-negative. A large part of the intestinal flora is not cultivable and knowledge of these bacteria is minimal. The composition of the normal flora may vary with the animal species, feed, and housing conditions including population density.

\section{THE NORMAL FLORA OF THE DIGESTIVE TRACT}

Most of the digestive tract is densely populated by bacteria. The digestive tract can be divided into distinct units, each providing conditions for the growth of a specific microflora.

The oral cavity is one of the most complex and heterogeneous microbiological habitats of the body. The bacterial flora present here includes both strict anaerobes and facultative anaerobic bacteria. Several antimicrobial substances have been 
identified in saliva, of which the most important are enzymes such as lysozyme and lactoperoxidase [32]. Despite the activity of these substances, the presence of food particles and epithelial debris makes the oral cavity a favorable habitat for microbial growth. Bacterial diversity in the microflora of the oral cavity is considerable and includes species like Corynebacterium spp., Haemophilus spp., Bacteroides spp., Fusobacterium spp., Actinomyces spp., Actinobacillus spp., Treponema spp., Micrococcus spp., Moraxella spp. and Neisseria spp. [29, 32, 55].

The stomach contains relatively few microorganisms due to its acidic environment. Hydrochloric acid produced in the stomach generates a $\mathrm{pH}$ value of nearly 2.0. The acidic environment functions as a microbiological barrier against the entry of foreign bacteria into the intestinal tract. Even if the bacterial content of the stomach is generally low, some acid-tolerant species are capable of colonizing this organ. Such bacteria include species of lactobacilli and streptococci [29, 32]. The gastric pathogen Helicobacter pylori is able to colonize the stomach of humans. $H$. pylori has also been isolated from the stomach of pigs and cats, and several other species of Helicobacter occur in the stomach of various animals [15].
The anterior part of the small intestine is acidic and resembles the stomach in terms of its microbial content - a microflora mainly consisting of Gram-positive species. The distal section of the small intestine has a less acidic $\mathrm{pH}$ value. This creates changes in the bacterial flora resulting in a richer and more complex microflora. In the lower ileum there are $10^{5}-10^{7}$ bacteria per gram. The present microflora includes species within the family Enterobacteriaceae and Bacteroides spp., in addition to lactobacilli and enterococci.

The large intestine contains an enormous microbial population. Four hundred species or more can be detected in the microflora. The bacterial population of the large intestine comprises mainly strict anaerobic bacteria such as Bacteroides spp., Fusobacterium spp., Clostridium spp., and Peptostreptococcus spp. Facultative anaerobes such as Escherichia coli, Klebsiella spp., Enterobacter spp., and Enterococcus spp. are also present in considerable numbers. Major differences exist between the intestinal microflora of each animal species as shown in Table I. From Table I it is clear that the concentration of the various bacteria in the intestines varies with species. $E$. coli and enterococci are the two most widespread groups among pets and farm

Table I. Normal fecal flora of some animal species (Log viable cells per $\mathrm{g}$ feces) ${ }^{\mathrm{a}}$.

\begin{tabular}{lccccc}
\hline Animal & $\begin{array}{c}\text { Escherichia } \\
\text { coli }\end{array}$ & $\begin{array}{c}\text { Clostridium } \\
\text { perfringens }\end{array}$ & Enterococci & $\begin{array}{c}\text { Bacteroides } \\
\text { spp. }\end{array}$ & Lactobacilli \\
\hline Cattle & 4.3 & 2.3 & 5.3 & 0 & 2.4 \\
Sheep & 6.5 & 4.3 & 6.1 & 0 & 3.9 \\
Horses & 4.1 & 0 & 6.8 & 0 & 8.0 \\
Pigs & 6.5 & 3.6 & 6.4 & 5.7 & 8.4 \\
Chickens & 6.6 & 2.4 & 7.5 & 0 & 0 \\
Rabbits & 2.7 & 0 & 4.3 & 8.6 & 8.6 \\
Dogs & 7.5 & 8.4 & 7.6 & 8.7 & 9.8 \\
Cats & 7.6 & 7.4 & 8.3 & 8.9 & 8.8 \\
Mice & 6.8 & 0 & 7.9 & 9.7 & 9.1 \\
Humans & 6.7 & 3.2 & 5.2 & & \\
\hline
\end{tabular}

${ }^{a}$ Median values from 10 individuals.

Adapted from [46] and [54]. 
animals. The delicate relation and ecological balance between the bacterial species of the normal flora of the intestines are so far poorly understood.

A molecular study of Bacteroides thetaiotaomicron [19] shows that a regulatory system mediated by FucR regulates the need of this commensal for nutrients and energy in a way that does not stimulate other competitors in the competitive ecosystem of the intestines.

The intestinal flora of mammals is responsible for a wide variety of metabolic reactions and assists in the enzymatic breakdown of food. The production of useful vitamins like niacin, vitamins B1, B2, B6, and $\mathrm{B} 12$, folic acid, biotin, and vitamin $\mathrm{K}$ involves the activity of microorganisms $[12,55]$. The enterobacterial flora plays a considerable role as one of the major defence mechanisms that protects the animal body against colonization by invading pathogens. The commensals and symbionts prevent this colonization by competing for nutrients and for attachment sites [53]. The normal flora plays an essential role in stimulating the production of cross-reactive antibodies. Components of the normal flora are important in preparing the immune system in the defence against pathogens thereby preventing infection or invasion [7].

The normal flora stimulates the development of certain tissues, like lymphatic tissue in the gastro-intestinal tract [12]. The microflora of ruminants plays a crucial role in the development of the rumen in the young ruminant.

The intestinal microflora is strongly influenced by diet. The addition of organic acids to the feed of fattening pigs contributes to an alteration (reduction) in the total number of bacteria, and to changes in the composition of the gut bacterial flora. Addition of organic acids to pig fodder results in increased growth, estimated at approximately 10-15\% [44].

The equilibrium of the normal flora can be disturbed by the effect of antibacterial compounds. It is suggested that exposure to antibacterial agents in any form will increase the prevalence of resistance to antibacterials among fecal bacteria [14, 28, 57, 63]. In the early 1950 s it was discovered that small quantities of penicillin added to the feed of young chickens led to a marked increase in growth. Since then a variety of chemicals has been used as feed additives for domestic animals in order to improve their growth response. Growth promoters include substances like antibacterials, anabolics, nonspecific chemicals (copper, arsenicals, cobalt, etc), and rumen fermentation modifiers [10]. The side effects following the use of antibacterials as feed additives has been a subject of controversy for several decades. As early as 1969 the "Swann-report" recommended that the use of antibacterials as growth promoters should follow clear guidelines in order to prevent development of resistant bacteria [4]. The most striking example of an unwanted side effect following the use of growth promoters was the development of vancomycin resistance in avian enterococci as a response to avoparcin exposure through feed. Avoparcin was banned as a feed additive for domestic animals in the European Union in 1997.

Several studies have investigated the colonization resistance [59] caused by normal flora bacteria against various potential pathogens $[16,61]$. There seems to be a reduced protection of the host against pathogenic bacteria when the normal flora is reduced by antimicrobial agents [60]. However, there is a disagreement as to which part of the microflora of the intestines is most important in colonization resistance.

The use of amoxicillin in a primate model resulted in the increased spread of E. coli from the rectum to the vagina [62]. Colonization resistance in this primate model could only partly be explained by the existence of lactobacilli in the vagina. However, the accumulation of $E$. coli around the urethral orifice increased the risk of urinary tract infection because the normal flora at the site was removed by amoxycillin. 
In general, the impression is that the normal flora predominantly consists of symbionts and commensals rather than opportunists. However, studies on growth and utilization of feed in animals fed with growth promoters like antibiotics and organic acids have indicated that an improved utilization of nutrients in the feed is caused by a reduced number of bacteria in the normal flora. The bacteria of the normal flora compete with the host to a certain degree for nutrients in the feed [39].

\section{THE NORMAL FLORA OF THE SKIN}

The majority of skin microorganisms are found in the most superficial layers of the epidermis and the upper parts of the hair follicles. The microflora is especially rich and abundant in warm and humid parts of the skin. The flora mainly consists of micrococci, coagulase-negative staphylococci (CNS), and corynebacteria. These are generally non-pathogenic and are considered to be commensal. However, CNS are often related to infections in hospitalized humans and are reported to be responsible for bovine mastitis [21]. In some individuals of a population, potentially pathogenic bacteria such as Staphylococcus aureus are part of the skin flora. Species within the CNS-group are often associated with multiple drug resistance. In addition to being normal flora bacteria, multiresistant coagulase-negative Staphylococcus spp. could possibly serve as gene donors to the more virulent $S$. aureus and Staphylococcus intermedius (associated with the canine species). The discovery of closely related plasmids and resistance elements among bacteria within the staphylococcal group [27, 49] suggests that horizontal gene transfer takes place. Such an exchange has been demonstrated both in the laboratory and on human skin [20]. Cycling of resistance determinants with commensal CNS is probably important for maintenance and spread of resistance in coagulasepositive staphylococci.

\section{THE NORMAL FLORA OF THE RESPIRATORY SYSTEM}

In healthy animals, the lower respiratory tract is normally free of bacterial flora. Healthy animals usually have no bacterial flora in the sinuses (in the upper respiratory tract). The nasopharynx is usually populated by a large number of bacterial species including staphylococci, $\alpha$-hemolytic streptococci and species within the Pasteurellaceae family.

\section{ANTIBIOTIC RESISTANCE IN THE BACTERIAL FLORA OF ANIMALS}

Testing the "normal flora" for occurrence of antibiotic resistance is not straightforward compared to testing the susceptibility of single isolates of bacterial pathogens from infections. During an active infection a specific pathogen will often dominate the area of infection normally populated by a diverse flora of commensals. The antibiotic resistance pattern found in one colony of the monoculture of a pathogen normally represents the causative pathogen of the particular infection. Studies on the antibiotic resistance of the normal flora should take into consideration that several species of bacteria with various levels of antibiotic resistance exist at the same site. Many normal flora species cannot be cultivated and many species occur in low numbers resulting in problems with isolation.

It is easier to detect a resistance gene in the flora as a bacterial community with molecular methods like polymerase chain reaction $(\mathrm{PCR})$ and to possibly quantify the gene dosage with for instance quantitative PCR, than to map the existence of resistance genes to certain species of bacteria.

An approach that seems to be common is to study resistance in a specific group of bacteria after primary isolation of these bacteria from the normal flora. Escherichia coli or coliform bacteria are frequently used as 
representatives of the enterobacteria in the intestinal flora often obtained from fecal samples.

Frequently, a certain number of primary colonies of the same species of bacteria is selected for further studies of antibiotic resistance. The way of selecting normal flora isolates for further study is crucial to the results obtained $[41,52]$.

\subsection{Escherichia coli in the normal fecal flora}

E. coli can be both a commensal and a potential pathogen, depending of the type of strain. Serotyping is commonly used to separate pathogenic from non-pathogenic variants of $E$. coli. It is documented that transfer of $\mathrm{R}$ plasmids occurs between strains of $E$. coli in the intestinal flora of animals, for instance in chickens [17]. Knowledge of the mechanisms of transfer of antibiotic resistance features between bacteria is better for $E$. coli compared to the other bacterial species studied and it is speculated that the antibiotic resistance level of normal flora coliforms may have an impact on pathogenic $E$. coli or other pathogenic enterobacteria like the Salmonella species. In fecal samples from different groups of hospitalized patients Österblad et al. [43] found that $E$. coli isolates were far more resistant than other enterobacteria in the fecal samples. They also found that the resistance level of $E$. coli was proportional to the level of exposure of the intestinal flora to antibiotics. Gellin et al. [14], however, found that the non-lactose-fermenting fecal isolates were more antibiotic-resistant than the lactose-fermenting isolates in three pig herds with three different histories of exposure to antibiotics.

Rapidly developing resistance against dihydrostreptomycin in $E$. coli of calves occurred in an experiment testing the effect of dihydrostreptomycin and neomycin on the normal flora [40]. This indicates that $E$. coli is a good candidate for studies on the antibiotic resistance level of the fecal normal flora. So far, there is no explanation for the difference between various bacterial species of the normal fecal flora in obtaining antibiotic resistance factors and further research on this topic will be valuable.

\subsection{Antibiotic resistance in $E$. coli of the normal fecal flora}

Normal fecal flora E. coli (1200 isolates) of healthy fattening pigs in ten different herds with a different history of antibiotic use was studied with respect to antibiotic resistance features and the genetic mechanisms responsible [51, 52]. The ten herds had different histories of exposure to antimicrobial agents for therapeutic purposes. Resistance against streptomycin, predominantly caused by the $\operatorname{str} A-s t r B$ gene pair, was found to be most common, followed by resistance against sulphonamides caused by sulI and sulII and tetracycline, predominantly caused by the class B and C determinants. The highest number of antibioticresistant $E$. coli was found in herds where the use of antimicrobial agents was considered high.

A higher proportion of the antibioticresistant isolates from herds with a history of high antibiotic use contained integrons compared to the resistant isolates from herds with a low use of antibiotics. The ant(3")Ia gene responsible for resistance to streptomycin/spectinomycin was detected as the sole gene cassette in $15 \mathrm{E}$. coli isolates harbouring class 1 integrons from 14 healthy animals on seven different farms. The study concludes that non-pathogenic $E$. coli from swine may represent a considerable reservoir of antibiotic resistance genes that might be transferable to pathogens.

In the study by Gellin et al. [14], the antibiotic resistance patterns of the Gramnegative fecal bacteria from pigs in three herds with different histories of antibiotic exposure were compared. The proportions of antibiotic-resistant and multi-resistant strains 
were greater among isolates from pigs in a herd where antibiotics had been used therapeutically compared to a herd where no antimicrobial agents had been used for 154 months. The results suggested that any form of antimicrobial exposure will increase the prevalence of antimicrobial resistance of bacteria.

Langlois et al. [25] found that $26 \%$ of the fecal coliform bacteria from pigs were resistant to tetracycline in a herd that was not exposed to antimicrobial agents. In a pig herd where antimicrobials were used only for therapeutic purposes, $76 \%$ of the fecal coliform isolates were resistant to tetracycline. In contrast, in a pig herd where the animals were continuously exposed to antibiotics, both as feed additives and therapeutic agents, almost $100 \%$ of the fecal coliform bacteria were tetracyclineresistant.

In using antibacterial drugs to control infection in animals, bacteria which are resistant to the drugs used will normally be selected and their establishment in the bacterial flora of the animal will be eased. However, in spite of the absence of selective pressure, antibiotic-resistant $E$. coli and other resistant enterobacteria settle in the intestinal flora of chickens $[11,18]$.

Gardner et al. [13] studied a human population on the Solomon Islands in 1968 which had not been exposed to commercially produced antibiotics. They detected $\mathrm{R}$ factors which mediated resistance to streptomycin and tetracycline in one unclassified bacterium from soil and from an E. coli strain in a human stool specimen.

The factors underlying the distribution of $\mathrm{R}$ plasmids with several resistance factors are probably important in this phenomenon. Resistance to drugs like heavy metals, for instance mercury (Tn21-related transposons and staphylococcal plasmids) and cadmium compounds (staphylococcal plasmids) [31] are shown to be located together with antibiotic resistance determinants on the same genetic structures. Drugs other than antibiotics in the environment may contribute to the distribution and maintenance of antibiotic resistance in normal flora bacteria.

\subsection{Environmental stress and antibiotic-resistant bacteria in swine}

Stress under transport, overcrowding in holding pens, and rough handling before slaughter result in increased shedding of antibiotic-resistant enteric bacteria in the environment according to a study by Molitoris et al. [36]. When pigs were exposed to excessively cold conditions, the combined resistance towards ampicillin and tetracycline in $E$. coli of the fecal flora increased significantly from 6 to $27 \%$, in a study by Moro et al. [37].

The same authors studied the effect of heat stress on the occurrence of antibiotic resistance in the $E$. coli of fecal flora of finishing slaughter hogs [38]. They discovered an increased level of antibiotic-resistant fecal $E$. coli in pigs kept at $+34{ }^{\circ} \mathrm{C}$ for $24 \mathrm{~h}$. The farm where these animals were kept had not used antimicrobial drugs in the feed for ten years. There was a significantly higher level of resistance against amikacin, ampicillin, cephalothin, neomycin and tetracycline from fecal samples when compared with pre-stress levels for $E$. coli. The high level of resistance persisted for ten days after heat stress, up until slaughter, for most of the antimicrobials mentioned. Following this, samples of different sections of the gastrointestinal tract were collected from another group of pigs after heat stress and compared with non-stressed animals. Results indicated that the $E$. coli which colonized the ileum and caecum had a higher level of resistance to ampicillin and tetracycline than the $E$. coli which colonized the colon and rectum. When animals were exposed to heat stress, resistance against ampicillin and tetracycline of $E$. coli in the lower digestive tract increased to a level similar to that observed 
in the ileum and caecum. Finally in an experiment in which they artificially increased intestinal motility, Moro et al. [38] found that the result was an increased occurrence of resistant $E$. coli in the colon and rectum.

It was verified that a higher level of ampicillin- and tetracycline-resistant E. coli existed in the caecum than in other segments of the intestinal tract. In animals with increased intestinal motility, the level of resistance increased for $E$. coli from the colon and rectum. Using chromium-EDTA as a marker, the authors found that heatstressed animals had a reduced intestinal transit time. These results support the hypothesis that there is an increased outflow of resistant organisms from the upper tract (ileum and caecum) to the lower tract (colon and rectum) under increased motility in the intestinal tract.

The results of Moro et al. [37, 38] point at an interesting aspect of the normal intestinal flora of pigs. The colon, a voluminous part of the intestinal tract, may contribute to a reduction in the level of antibiotic resistance in the normal $E$. coli flora descending from the upper exposed parts of the intestine. A normal intestinal bacterial flora of pigs which is functional may play an important role in reducing the spread of antibiotic-resistant bacteria from the feces into the environment. Meat products for human consumption may be vectors of antibiotic-resistant bacteria from resistant porcine fecal flora. This field requires more research in the future to verify various hypotheses and investigate the situation in other animal species. Minton et al. [35] studied the occurrence of antibiotic-resistant fecal coliforms from a domestic dog with an acute enteric infection. The 10-monthold dog had no prior contact with antibiotic agents. They found that fecal coliform isolates from the acute phase of enteritis were in general resistant to a wide variety of antibiotics while after restoration such coliform isolates had lost their resistance to several antibiotics. However, low numbers of bacteria with a wide spectrum of resistance could still be isolated from the feces of the dog up to one year later. This case may be similar to the stress-induced detection of resistant bacteria from pigs, discussed above. The reduced passage time for intestinal contents during acute enteritis may have allowed more resistant bacteria to pass from the upper part of the intestine into the rectum than is usual in a healthy situation.

Langlois and Dawson [24] found that loading and transporting pigs for $30 \mathrm{~min}$ significantly increased the portion of antimicrobial-resistant Gram-negative enteric bacteria in feces. The mean number of antimicrobial agents in the resistance patterns of the bacteria increased during loading and transportation. These changes in the resistance level of the bacterial flora lasted only one day.

Langlois et al. [26] found that age and housing location had an effect on antibiotic resistance of the fecal coliform flora from pigs in a herd that was not exposed to antibiotics. Pigs less than seven months of age had a higher level of antibiotic resistance than older pigs. Similarly, pigs in the finishing unit had a higher level of antibiotic resistance than those in the farrowing house and on pasture.

These studies indicate that other factors in addition to exposure to antibiotics are important in deciding the level of antibiotic resistance in the fecal coliform flora of pigs.

\section{TRANSFER OF ANTIBIOTIC- RESISTANT BACTERIA FROM ANIMALS TO MAN}

Antibiotic resistance was transferred from cultures of $E$. coli of animal and human origin taken by mouth in large doses to the resident $E$. coli of the alimentary tract of a human being [50]. However, large doses of donor bacteria had to be ingested to obtain a measurable transfer and the resistant recipient strains did not persist for more than a 
few days in the feces. The animal E. coli strains colonized the intestines less efficiently than the human donor strains.

Linton et al. [30] studied whether resistant $E$. coli strains from commercially purchased chicken carcasses were transferred and established as a part of the coliform flora of human consumers. Five volunteers who had not received antibiotics for at least one year handled, prepared and ate during a period of three months, in their homes, a total of 15 frozen chickens purchased locally. The chickens were sampled for isolation and characterization of E. coli. The isolates were characterized by resistance patterns, serotyping, and plasmid content. Similarly, the predominant $E$. coli serotypes in the fecal flora of each of the volunteers were determined over a three-month period. One of the five volunteers became colonized by five of the 14 resistant $E$. coli strains found in one chicken after thawing. The strains were transferred during the handling of the raw meat before heating and eating, and they stayed in the fecal flora for ten days. This study illustrates that a resistant fecal normal flora in meat-producing animals may have an impact on the resistance of the normal flora of human consumers.

Manie et al. [34] studied meat from cattle which had been administered subtherapeutic doses of antibiotics in the feed. They found a higher incidence of antibiotic-resistant bacteria from freshly slaughtered meat in the abattoirs than in the retail samples. Some of the resistant strains could be isolated both in the meat at the abattoir and in the meat from the retail store. They indicate that a lack of selective pressure leads to loss of resistance in bacteria and that additional susceptible bacterial flora contaminates the meat on the way to the retailers and therefore dilutes the more resistant abattoir flora before the meat is sold at the retail store. Similar results were found when the same research group studied the bacterial flora of newly slaughtered and retail chicken [33]. These results underline the importance of having a low antibiotic exposure of the ani- mals before they are slaughtered to make sure that as few resistant bacteria as possible are exposed to the meat consumer.

\subsection{Antibiotics as feed additives}

The use of avoparcin as a growth promoter in poultry and pig feed in Europe has led to the occurrence of vancomycin-resistant enterococci (VRE) in the normal gut flora of these animals [22]. In the USA there has been no use of avoparcin as a growth promoter in animal farming and the enterococci of the farm animals are not resistant to vancomycin. However, carriage rates of VRE in hospital patients are higher in the USA than in Europe [6]. The use of glycopeptides in US hospitals is higher than in European hospitals. This probably explains the difference in carriage of VRE among humans in these areas. Poultry farmers and a relatively low - but still detectable - part of the general human population in European countries carries VRE in their normal fecal flora.

Since 1997 there has been a ban on the use of avoparcin in feed for farm animals in Europe and the occurrence of VRE has declined in poultry meat [23]. A decline in the number of VRE carriers among the human population from $12 \%$ in 1994 to $6 \%$ in 1996 and 3\% in 1997 was detected in the Saxony-Anhalt region in Germany [23].

In Enterococcus faecium isolates from the normal fecal flora of broilers and pigs in Denmark, Finland, and Norway a clear correlation was found between resistance to various antibiotics used as feed additives and the amount of the various drugs used in the different countries [3].

Normal fecal flora Enterococcus faecalis and faecium isolates from broilers, pigs, and healthy humans in the community, in Denmark, were compared with regard to resistance phenotypes and genes [2]. Widespread resistance to chloramphenicol, kanamycin, macrolides, streptomycin, and tetracycline was detected among isolates from all three 
sources. Resistance to avilamycin used as a feed additive for poultry was common (35\%) among the poultry isolates whereas it was not detected among the isolates from pigs and humans. Similarly, 10 and $17 \%$ of the isolates from poultry and pigs, respectively, were resistant to vancomycin whereas none of the human isolates were resistant to vancomycin. Avoparcin was used as a feed additive in Denmark for poultry and pigs until this practice was banned in 1995, which probably explains the continuous occurrence of VRE in these species. Even though the proportion of resistant strains in the normal fecal flora of these three hosts varied, the authors conclude that similar resistance patterns and resistance genes in many of the isolates indicate that transmission of resistant enterococci or resistance genes takes place between humans, broilers, and pigs.

Bager et al. [5] found that the decrease in VRE in the normal fecal flora of broilers was statistically significant in the two-anda-half-year period after the ban of avoparcin as a feed additive while there was no such decline in the normal fecal flora of pigs. In pigs, the use of macrolides as therapeutic agents and as growth promoters probably co-selected the VRE since it has been demonstrated that the vanA gene and the erm $B$ gene are located on the same transferable genetic element [1].

Four years after the ban of avoparcin used in broiler feed, environmental samples from Norwegian broiler farms were found to contain VRE. The environmental samples were taken from empty clean broiler houses after depopulation and clean-up. Within three weeks after introduction in the farm, the broilers tested positive for VRE indicating the strong relation between the environmental bacterial flora and the normal flora of the chicken. However, the VRE were not isolated from the hatchery serving the farms [9].

Seventy-three broiler farms exposed to avoparcin as a feed additive in the period from 1986 to 1995 and 74 unexposed farms were investigated for the occurrence of VRE three years after the use of avoparcin was stopped [8]. VRE were isolated from $99 \%$ and $11 \%$ of the fecal poultry samples from exposed and unexposed farms, respectively. VRE were also isolated from 13 out of 73 $(18 \%)$ and one out of $74(<1 \%)$ fecal samples from farmers on exposed and unexposed farms, respectively.

Transfer of vanA between broilers and humans at avoparcin-exposed farms can occur directly by transfer of VRE strains as well as through horizontal spread of $\operatorname{Tn} 1546$ between bacteria [48].

The results of the studies discussed strongly indicate the importance of the antibiotic selective pressure exerted by antibiotic drugs used as growth promoters for the presence of antibiotic-resistant bacteria in the normal flora of animals and in the meat products from commercial animal husbandry. Additionally, the results underline the role of animal products for the spread of resistant bacteria and transferable resistance genes to humans in the community.

\subsection{Source of antibiotic resistance genes in the normal bacterial flora}

The normal bacterial flora establishes itself in the various parts of the newborn animal shortly after birth and the source is the close environment, normally the bacterial flora of the mother. Later, the normal flora of the animal digestive tract will be influenced by the intake of fodder. Plants are important ingredients in the feed of most farm animals and it could be tempting to believe that bacteria associated with the plant environment transfer antibiotic resistance factors to the normal flora bacteria of the animals. However, Österblad et al. [42] studied the antimicrobial susceptibility of bacteria within Enterobacteriaceae isolated from vegetables prepared for human consumption. They concluded that bacteria from vegetables could not be responsible for the 
high prevalence of resistant bacteria of the Enterobacteriaceae in the human fecal flora in Finland.

\subsection{Consequences of antibiotic resistance in the normal flora of animals}

Several studies indicate that there is some degree of communication between normal flora bacteria and pathogens. This communication has so far been considered as only negative, in particular because a resistant normal flora population will probably contribute to the general increase in antibiotic resistance in bacterial pathogens.

It may be speculated that a normal bacterial flora without antibiotic resistance factors and little capacity to acquire resistance genes could have a dramatically negative effect for the host animal. Large parts of such a bacterial flora could be wiped out under a regular therapeutic treatment with generally administered antibiotic drugs. As a consequence, antibiotics would not be able to be used in curing infections in animals like horses, rodents, ruminants, pigs, and probably birds because the vital normal flora of important parts of the digestive system would be destroyed for short or long periods of time. As a result, secondary infections would occur more often, requiring a greater use of antibiotics. This vicious circle may be avoided by a normal bacterial flora that is able to react with development of antibiotic resistance in response to exposure to antibiotics.

According to these speculations, the potential transfer of resistance genes between normal flora bacteria and bacterial pathogens may only be considered as a sideeffect of the use of antibiotics. Considering this field of research from such a viewpoint further underlines the need to restrict the use of antibiotics in animals for only strict therapeutic purposes in settings where the risks of developing infectious diseases are reduced to a minimum.
According to van den Bogaard and Stobberingh [56], diminishing the need for antibiotics is the only possible way of controlling the development of antibiotic resistance in large groups of animals. Improvement of animal husbandry systems, feed composition, vaccination, eradication programs for specific pathogens, and stopping the use of feed additives for growth promotion will be very important elements in reaching this goal. Van den Bogaard and Stobberingh [56] state that abolishing the use of antibiotics as feed additives alone will reduce the use of antibiotics in animals by nearly $50 \%$ on a worldwide basis.

\section{RESEARCH NEEDS}

The possible link between the use of antibiotics in food-producing animals and the development of antibiotic-resistant bacteria among humans has been discussed in several studies. Shryock [47] states that studies often try to establish a "cause and effect" relationship between the use of antibiotics in food animals and treatment failures in human disease on the basis of data on antibiotic use, in vitro determinations of antibiotic susceptibility of animal and human isolates, results from controlled animal experiments, or epidemiological data. Shryock [47] suggests that the impact of the use of antibiotics in animals on antibiotic resistance problems in bacterial pathogens of humans can only be assessed by comprehensively organizing the mentioned approaches via a concerted and coordinated effort through a multinational programme.

In such a coordinated effort it is important to include studies on the development of antibiotic resistance in the normal bacterial flora of production animals.

The normal bacterial flora of the intestines may have an antibiotic-destroying activity in addition to being in the possession of antibiotic resistance genes according to van der Waaij et al. [58]. This phenomenon might be one of the factors 
behind intestinal colonization resistance caused by the normal bacterial flora. The processes responsible for making bacteria antibiotic-resistant may in several cases be the same as those destroying or inactivating the antibiotics. This hypothesis turns antibiotic resistance of the normal intestinal flora into a beneficial feature that ensures some degree of colonization resistance against potential bacterial pathogens.

A hypothetically permanent susceptible normal bacterial flora may be eradicated or seriously disturbed thus disrupting its balance for long periods resulting in negative effects on the host. An antibiotic-resistant normal bacterial flora may stop invading pathogens like salmonella bacteria through "colonization resistance" even if the animal has been given antibiotics for a reason. In fact, in some environments in which drugs are used in abundance an antibioticresistant bacterial flora probably protects individuals from being infected by pathogens.

Comprehensive studies of the development of antibiotic resistance in the bacterial species of the normal flora of animals should be planned keeping an open mind about results from earlier studies which indicate that the normal flora is more beneficial for the host than simply delivering antibiotic resistance genes to the pathogens that come into contact with the flora. Research should be performed to investigate which feed factors and management modifications improve animal health and growth without increasing the levels of antibiotic resistance in the important normal flora. Problems related to the development of antibiotic resistance in bacterial pathogens will create strong motivation for intense activity in this research field.

In the future, more importance must be attached to considering the normal bacterial flora of all sites on the animal as part of the "scenario" when discussing the use of antibiotic drugs in animal husbandry in general.

\section{REFERENCES}

[1] Aarestrup F.M., Characterization of glycopeptide-resistant enterococcus faecium (GRE) from broilers and pigs in Denmark: genetic evidence that persistence of GRE in pig herds is associated with coselection by resistance to macrolides, J. Clin. Microbiol. 38 (2000) 2774-2777.

[2] Aarestrup F.M., Agerso Y., Gerner-Smidt P., Madsen M., Jensen L.B., Comparison of antimicrobial resistance phenotypes and resistance genes in Enterococcus faecalis and Enterococcus faecium from humans in the community, broilers, and pigs in Denmark, Diagn. Microbiol. Infect. Dis. 37 (2000) 127-137.

[3] Aarestrup F.M., Kruse H., Tast E., Hammerum A.M., Jensen L.B., Associations between the use of antimicrobial agents for growth promotion and the occurrence of resistance among Enterococcus faecium from broilers and pigs in Denmark, Finland, and Norway, Microb. Drug Resist. 6 (2000) 63-70.

[4] Anonymous, Joint Committee on the use of Antibiotics in Animal Husbandry and Veterinary Medicine, Her Majesty's Stationary Office, London, UK, Report, 1969, pp. 1-83.

[5] Bager F., Aarestrup F.M., Madsen M., Wegener H.C., Glycopeptide resistance in Enterococcus faecium from broilers and pigs following discontinued use of avoparcin, Microb. Drug Resist. 5 (1999) 53-56.

[6] Bates J., Epidemiology of vancomycin-resistant enterococci in the community and the relevance of farm animals to human infection, J. Hosp. Infect. 37 (1997) 89-101.

[7] Blum S., Alvarez S., Haller D., Perez P., Schiffrin E.J., Intestinal microflora and the interaction with immunocompetent cells, Antonie van Leeuwenhoek 76 (1999)199-205.

[8] Borgen K., Simonsen G.S., Sundsfjord A., Wasteson Y., Olsvik Ø., Kruse H., Continuing high prevalence of VanA-type vancomycin-resistant enterococci on Norwegian poultry farms three years after avoparcin was banned, J. Appl. Microbiol. 89 (2000) 478-485.

[9] Borgen K., Sørum M., Kruse H., Wasteson Y., Persistence of vancomycin-resistant enterococci (VRE) on Norwegian broiler farms, FEMS Microbiol. Lett. 191 (2000) 255-258.

[10] Brander G.C., Pugh D.M., Bywater R.J., Veterinary Applied Pharmacology \& Therapeutics, Ballière Tindall, London, UK, 1982.

[11] Chaslus-Dancla E., Gerbaud G., Lagorce M., Lafont J.P., Courvalin P., Persistence of an antibiotic resistance plasmid in intestinal Escherichia coli of chickens in the absence of selective pressure, Antimicrob. Agents Chemother. 31 (1987) 784-788.

[12] Clarke R.T.J., Bauchop T., Microbial Ecology of the Gut, Academic Press Inc. London, UK, 1977. 
13] Gardner P., Smith D.H., Beer H., Moellering R.C. $\mathrm{Jr}$., Recovery of resistance $(\mathrm{R})$ factors from a drug-free community, Lancet 2 (1969) 774-776.

[14] Gellin G., Langlois B.E., Dawson K.A., Aaron D.K., Antibiotic resistance of gram-negative enteric bacteria from pigs in three herds with different histories of antibiotic exposure, Appl. Environ. Microbiol. 55 (1989) 2287-2292.

[15] Glupczynski Y., Topley \& Wilson's Microbiology and Microbial Infections, Vol. 3, Arnold, Hodder Headline Group, London, UK, 9th Ed., 1998, pp. 581-591.

[16] Gorbach S.L., Barza M., Giuliano M., Jacobus N.V., Colonization resistance of the human intestinal microflora: testing the hypothesis in normal volunteers, Eur. J. Clin. Microbiol. Infect. Dis. 7 (1988) 98-102.

[17] Guillot J.F., Boucaud J.L., In vivo plasmid transfer between strains of Escherichia coli in the chicken digestive system (in French), Pathol. Biol. (Paris) 36 (1988) 655-659.

[18] Guillot J.F., Chaslus-Dancla E., Lafont J.P., Spontaneous implantation of antibiotic-resistant Enterobacteriaceae in the digestive tract of chickens in the absence of selective pressure, Antimicrob. Agents Chemother. 12 (1977) 697-702.

[19] Hooper L.V., Xu J., Falk P.G., Midtvedt T., Gordon J.I., A molecular sensor that allows a gut commensal to control its nutrient foundation in a competitive ecosystem, Proc. Natl. Acad. Sci. USA 96 (1999) 9833-9838.

[20] Jaffe H.W., Sweeney H.M., Nathan C., Weinstein R.A., Kabins S.A., Cohen S., Identity and interspecific transfer of gentamicin-resistance plasmids in Staphylococcus aureus and Staphylococcus epidermidis, J. Infect. Dis. 141 (1980) 738-747.

[21] Jarp J., Classification of coagulase-negative staphylococci isolated from bovine clinical and subclinical mastitis, Vet. Microbiol. 27 (1991) 151-158.

[22] Klare I., Heier H., Claus H., Reissbrodt R., Witte W., vanA-mediated high-level glycopeptide resistance in Enterococcus faecium from animal husbandry [published erratum appears in FEMS Microbiol Lett 127 (1995) 273], FEMS Microbiol. Lett. 125 (1995) 165-171.

[23] Klare I., Badstubner D., Konstabel C., Böhme G., Claus H., Witte W., Decreased incidence of VanA-type vancomycin-resistant enterococci isolated from poultry meat and from fecal samples of humans in the community after discontinuation of avoparcin usage in animal husbandry, Microb. Drug Resist. 5 (1999) 45-52.

[24] Langlois B.E., Dawson K.A., Antimicrobial resistance of gram-negative enteric bacteria from pigs in a nonantimicrobial-exposed herd before and after transportation, J. Food Prot. 62 (1999) 797 799
[25] Langlois B.E., Dawson K.A., Cromwell G.L., Stahly T.S., Antibiotic resistance in pigs following a 13 year ban, J. Anim. Sci. 62 (1986) 18-32.

[26] Langlois B.E., Dawson K.A., Leak I., Aaron D.K., Effect of age and housing location on antibiotic resistance of fecal coliforms from pigs in a nonantibiotic-exposed herd, Appl. Environ. Microbiol. 54 (1988) 1341-1344.

[27] Leelaporn A., Paulsen I.T., Tennent J.M., Littlejohn T.G., Skurray R.A., Multidrug resistance to antiseptics and disinfectants in coagulase-negative staphylococci, J. Med. Microbiol. 40 (1994) 214-220.

[28] Levy S.B., The Antibiotic Paradox. How Miracle Drugs are Destroying the Miracle, Plenum Press, New York, USA, 1992.

[29] Linton A.H., Microbes, Man and Animals. The Natural History of Microbial Interactions, John Wiley and Sons, UK, 1982.

[30] Linton A.H., Howe K., Bennett P.M., Richmond M.H., Whiteside E.J., The colonization of the human gut by antibiotic resistant Escherichia coli from chickens, J. Appl. Bacteriol. 43 (1977) 465469

[31] Lyon B.R., Skurray R., Antimicrobial resistance of Staphylococcus aureus: Genetic basis, Microbiol. Rev. 51 (1987) 88-134

[32] Madigan M.T., Martinko J.M., Parker J., Brock Biology of Microorganisms, Prentice-Hall International Limited, London, UK, 1977.

[33] Manie T., Khan S., Brozel V.S., Veith W.J., Gouws P.A., Antimicrobial resistance of bacteria isolated from slaughtered and retail chickens in South Africa, Lett. Appl. Microbiol. 26 (1998) 253-258.

[34] Manie T., Brozel V.S., Veith W.J., Gouws P.A., Antimicrobial resistance of bacterial flora associated with bovine products in South Africa, J. Food Prot. 62 (1999) 615-618.

[35] Minton N.P., Marsh J., Atkinson T., The R-factors of multiple antibiotic resistant faecal coliforms isolated from a domestic dog, J. Appl. Bacteriol. 55 (1983) 445-452.

[36] Molitoris E.D., Fagerberg L., Quarles C.L., Krichevsky M.I., Changes in antimicrobial resistance in fecal bacteria associated with pig transit and holding times at slaughter plants, Appl. Environ. Microbiol. 53 (1987) 1307-1310.

[37] Moro M.H., Beran G.W., Hoffman L.J., Griffith R.W., Effects of cold stress on the antimicrobial drug resistance of Escherichia coli of the intestinal flora of swine, Lett. Appl. Microbiol. 27 (1998) 251-254.

[38] Moro M.H., Beran G.W., Griffith R.W., Hoffman L.J., Effects of heat stress on the antimicrobial drug resistance of Escherichia coli of the intestinal flora of swine, J. Appl. Microbiol. 88 (2000) 836-844.

[39] Mroz Z., Jongbloed A.W., Partanen K.H., Vreman K., Kemme P.A., Kogut J., The effects of 
calcium benzoate in diets with or without organic acids on dietary buffering capacity, apparent digestibility, retention of nutrients, and manure characteristics in swine, J. Anim. Sci. 78 (2000) 2622-2632.

[40] Mylrea P.J., Passage of antibiotics through the digestive tract of normal and scouring calves and their effect upon the bacterial flora, Res. Vet. Sci. 9 (1968) 5-13.

[41] Österblad M., Leistevuo T., Huovinen P., Screening for antimicrobial resistance in fecal samples by the replica plating method, J. Clin. Microbiol. 33 (1995) 3146-3149.

[42] Österblad M., Pensala O., Peterzens M., Heleniusc H., Huovinen P., Antimicrobial susceptibility of Enterobacteriaceae isolated from vegetables, J. Antimicrob. Chemother. 43 (1999) 503-509.

[43] Österblad M., Hakanen A., Manninen R., Leistevuo T., Peltonen R., Meurman O., Huovinen P., Kotilainen P., A between-species comparison of antimicrobial resistance in enterobacteria in fecal flora, Antimicrob. Agents Chemother. 44 (2000) 1479-1484.

[44] Øverland M., Granli T., Kjos N.P., Fjetland O., Steien S.H., Stokstad M., Effect of dietary formates on growth performance, carcass traits, sensory quality, intestinal microflora, and stomach alterations in growing-finishing pigs, J. Anim. Sci. 78 (2000) 1875-1884.

[45] Pelczar M.J. Jr., Reid R.D., Microbiology, McGraw-Hill Book Company, New York, 1972.

[46] Rosebury T., Microorganisms Indigenous to Man, McGraw-Hill, New York, 1962.

[47] Shryock T.R., Relationship between usage of antibiotics in food-producing animals and the appearance of antibiotic resistant bacteria, Int. J. Antimicrob. Agents 12 (1999) 275-278.

[48] Simonsen G.S., Haaheim H., Dahl K.H., Kruse H., Løvseth A., Olsvik Ø., Sundsfjord A., Transmission of VanA-type vancomycin-resistant enterococci and $v a n A$ resistance elements between chicken and humans at avoparcin-exposed farms, Microb. Drug Resist. 4 (1998) 313-318.

[49] Skurray R.A., Firth N., Molecular evolution of multiply-antibiotic-resistant staphylococci, Ciba Found. Symp. 207 (1997) 167-183; discussion 183-191.

[50] Smith H.W., Transfer of antibiotic resistance from animal and human strains of Escherichia coli to resident $E$. coli in the alimentary tract of man, Lancet 1 (1969) 1174-1176.
[51] Sunde M., Sørum H., Characterization of integrons in Escherichia coli of the normal intestinal flora of swine, Microb. Drug Resist. 5 (1999) 279-287.

[52] Sunde M., Fossum K., Solberg A., Sørum H., Antibiotic resistance in Escherichia coli of the normal intestinal flora of swine, Microb. Drug Resist. 4 (1998) 289-299.

[53] Tancrede C., Role of human microflora in health and disease, Eur. J. Clin. Microbiol. Infect. Dis. 11 (1992) 1012-1015.

[54] Todar K., The Bacterial Flora of Humans, http:// www.bact.wisc.edu./Bact303/Bact303normalflora, University of Wisconsin-Madison, USA, 2000.

[55] Tortora G.J., Funke B.R., Case C.L., Microbiology: An introduction, Benjamin/Cummings Publishing Company Inc. Redwood City, CA, USA, 1989.

[56] van den Bogaard A.E., Stobberingh E.E., Antibiotic usage in animals: impact on bacterial resistance and public health, Drugs 58 (1999) 589607.

[57] van den Bogaard A.E., Stobberingh E.E., Epidemiology of resistance to antibiotics. Links between animals and humans, Int. J. Antimicrob. Agents 14 (2000) 327-335.

[58] van der Waaij D., Nord C.E., Development and persistence of multi-resistance to antibiotics in bacteria; an analysis and a new approach to this urgent problem, Int. J. Antimicrob. Agents 16 (2000) 191-197.

[59] van der Waaij D., de Vries Berghuis J.M., Lekkerkerk van der Wees J.E.C., Colonization resistance of the digestive tract in conventional and antibiotic-treated mice, J. Hyg. 69 (1971) 405-411.

[60] van der Waaij D., de Vries-Hospers H.G., Welling G.W., The influence of antibiotics on gut colonization, J. Antimicrob. Chemother. 18 Suppl. C (1986) 155-158.

[61] Wells C.L., Maddaus M.A., Jechorek R.P., Simmons R.L., Role of intestinal anaerobic bacteria in colonization resistance, Eur. J. Clin. Microbiol. Infect. Dis. 7 (1988) 107-113.

[62] Winberg J., Herthelius-Elman M., Möllby R., Nord C.E., Pathogenesis of urinary tract infection - experimental studies of vaginal resistance to colonization, Pediatr. Nephrol. 7 (1993) 509-514.

[63] Wray C., Some aspects of the occurrence of resistant bacteria in the normal animal flora, J. Antimicrob. Chemother. 18 Suppl. C (1986) 141-147. 